\title{
Admission and adjustment of residents in homes for the elderly
}

\author{
A. H. PATTIE AND C. J. GILlEARD \\ From Clifton Hospital, York
}

SUMMARY This paper discusses the relationship between psychological variables, a brief cognitive measure and a behavioural rating scale, and the subsequent adjustment of a group of elderly people newly admitted to a social services home for the elderly. It shows that, in this sample, three groups can be identified: a fairly independent group of people who show no apparent deterioration in functioning during the first year of admission; a more dependent group who show loss of functioning during the same period; and a third group who show an immediate negative effect from admission, and who have a poor outcome. We comment on the lack of evidence in support of a general negative relocation effect, and on the value of the procedures used.

Under the 1948 National Assistance Act, local authorities were enabled to provide 'residential accommodation for persons who, by reason of age, infirmity or any other circumstances, are in need of care and attention which is not otherwise available at the time.' Because of the absence of more detailed criteria for admission, there is inevitably a likelihood of misplacement of people of greater independence and also of those with excessive disabilityresidents admitted who do not need the degree of support offered by the home, and others admitted whose disability is such that the home cannot successfully provide for them. Coleman (1975) quotes studies which suggest a misplacement rate of between $20 \%$ and $60 \%$ of residents considered to need a less dependent regime, for example, sheltered housing, community support, and so on. On the other hand, social services departments have noted an increase in the age and dependency of elderly people coming into their care during the last decade (Department of Health and Social Security, 1977).

Our own studies have indicated a significant overlap in behavioural competence between residents in social services homes for the elderly (Part III accommodation) and those receiving long term hospital care (Gilleard and Pattie, 1977). Other workers (Smith and Lowther, 1976) have criticised the admission to residential homes of ill and disabled people with problems of dementia and incontinence which would have been better dealt with by admission to hospital. The increasing number of elderly people in the general population underlines the need for accurate placement of the elderly to maximise the usefulness of the resources available.

The elderly who need increased care may be moved from their homes and provided with residential care in a hospital, a nursing home, or in social services accommodation, etc., or they may be transferred from one type of residential care to another. The effect of such relocation has generally been held responsible for deleterious changes: either increased mortality (Lawton and Nahemow, 1973) or deterioration in psychological and physical functioning (Miller and Leiberman, 1965). This has been termed the 'negative relocation effect'. However, most of these studies have been carried out in the United States of America, and few have looked at transfer from the community to a residential setting. The present study, which is part of a series of investigations into the psychological assessment of the elderly in need of care, was designed to focus on the relationship of mental and behavioural disability to the subsequent adjustment of residents admitted to a newly opened home for the elderly with $\mathbf{5 0}$ beds.

\section{Method}

The psychological procedures used in the investigation were the Clifton Assessment Schedule (CAS) and the Shortened Stockton Geriatric Rating Scale (SSGRS) (Pattie and Gilleard, 1975; Gilleard and Pattie, 1977).

The CAS consists of three short tests measuring information/orientation, basic mental abilities, and psychomotor skill. This 10-minute test of mental 
functioning was administered to each new resident by a psychologist shortly after admission. The SSGRS is an 18-item rating scale designed to measure four aspects of behavioural disability-'physical disability'; 'apathy / inactivity'; 'communication problems'; and 'socially disruptive behaviour'. These are combined to give a total disability score. This rating scale was completed by relatives or social workers for each resident before he or she was admitted to the home. Shortly after admission, two of the staff repeated the rating scales to measure the residents' behaviour during the first few weeks of their stay. These two procedures (the CAS and the SSGRS) were used again six months and one year after admission. In order to evaluate each resident's adjustment a year after admission, independently of the psychological assessment, the following method was adopted. All the senior staff of the home rated each of the residents still in care on three scales, covering their social adjustment, emotional stability, and suitability for the type of accommodation. A compositive adjustment score was obtained for these three scales, and the group was divided into two at the median score, thus creating two groups, termed low and high adjustment groups. A third group was formed from those who had died or who had been transferred to long-term hospital care. The relationship of the CAS and SSGRS scores to their adjustment one year later was investigated.

\section{Results}

During the year after admission, three residents were transferred either to other Part III or to independent accommodation and $\mathbf{1 0}$ had died or been transferred to long-term hospital care. Of the remaining 34, 17 (five men and 12 women) were in the low adjustment group, and 17 (again five men and 12 women) were in the better adjusted group. These three main groups were distinguished and designated A (died or hospitalised), B (low adjustment), and C (high adjustment). The Table presents the mean scores for each of the three groups at six-monthly intervals, with pre-admission Stockton rating scores and ages on admission.

One-way analyses of variance were carried out to test for the significance of differences between the three groups. They did not differ significantly on age, but their Stockton rating scale scores showed significant differences throughout the period of study. Group C (high adjustment) showed a consistently lower level of behavioural disability compared with the low adjustment group; also, they showed no evidence of behavioural deterioration over the one-year period. On the other hand, group B (low adjustment) showed a significant deterioration from the time of their initial assessment to their final assessment one year later $P<0.01$ ). Group A, those who died or were permanently hospitalised, did not differ significantly in their pre-admission rating from either of the other two groups, but immediately after admission their rated behavioural disability was significantly greater than that of the high adjustment group $(P<0.001)$, but not different from that of the low adjustment group; Group A also showed a significant increase in their behavioural disability over time $(\mathrm{P}<0.001)$. In particular, Group A scores immediately before and after admission showed a marked increase in rated disability $(P<0 \cdot 01)$. Since neither of the other groups showed any change consequent upon admission, the possibility is raised of a causal relationship between their ultimate status and the deleterious effect of admission.

Post-admission testing on the CAS did not reveal any great differences in cognitive status between the two groups, which suggests that the decline in behaviour following admission is unlikely to be the result of cognitive impairment among members of Group A. To see if the deterioration was specifically associated with increased disorientation and confusion in Group A, the relationship was investigated between the scores on the information/orientation section of the CAS and outcome. It was hypothesised that Group A may have been more disorientated, although behaviourally able to cope in their familiar surroundings before admission;

Table Mean age, CAS, and SSGRS scores for the three groups

\begin{tabular}{|c|c|c|c|c|c|}
\hline & & Pre-admission & Post-admission & 6 months & 12 months \\
\hline $\begin{array}{l}\text { GROUP A } \\
\text { (died or hospitalised) } \\
\text { Age }=82 \cdot 4(6 \cdot 6)\end{array}$ & $\begin{array}{l}\text { SSGRS total } \\
\text { CAS total }\end{array}$ & $\begin{array}{l}n=9 \\
8 \cdot 0(2 \cdot 2) \\
-\end{array}$ & $\begin{array}{l}n=10 \\
13 \cdot 9(4 \cdot 9) \\
19 \cdot 8(9 \cdot 8)\end{array}$ & $\begin{array}{l}n=4 \\
22 \cdot 3(1 \cdot 2) \\
3 \cdot 8(4 \cdot 8)\end{array}$ & $\overline{-}$ \\
\hline $\begin{array}{l}\text { GROUP B } \\
\text { (low adjustment) } \\
\text { Age }=80.0(6.9)\end{array}$ & $\begin{array}{l}\text { SSGRS total } \\
\text { CAS total }\end{array}$ & $\begin{array}{l}n=14 \\
11 \cdot 2(5 \cdot 3)\end{array}$ & $\begin{array}{l}n=17 \\
11 \cdot 5(5 \cdot 6) \\
21 \cdot 0(8 \cdot 9)\end{array}$ & $\begin{array}{l}n=17 \\
14 \cdot 0(4 \cdot 6) \\
19 \cdot 6(8 \cdot 5)\end{array}$ & $\begin{array}{l}n=17 \\
17 \cdot 3(4 \cdot 6) \\
17 \cdot 7(9 \cdot 0)\end{array}$ \\
\hline $\begin{array}{l}\text { GROUP C } \\
\text { (high adjustment) } \\
\text { Age }=78 \cdot 6(7 \cdot 2)\end{array}$ & $\begin{array}{l}\text { SSGRS total } \\
\text { CAS total }\end{array}$ & $\begin{array}{l}n=12 \\
5 \cdot 9 \\
-\end{array}$ & $\begin{array}{l}n=17 \\
6 \cdot 1(3 \cdot 2) \\
25 \cdot 3(6 \cdot 0)\end{array}$ & $\begin{array}{l}n=17 \\
7 \cdot 9(4 \cdot 9) \\
25 \cdot 8(7 \cdot 4)\end{array}$ & $\begin{array}{l}n=17 \\
7 \cdot 9(4 \cdot 7) \\
27 \cdot 4(6 \cdot 5)\end{array}$ \\
\hline
\end{tabular}


thus as a group they were more vulnerable to the stress of relocation. However, the results from the information/orientation test failed to confirm the hypothesis, because no differences were observed between the groups on this measure. The finding of an immediate decline in behavioural competence in Group $\mathbf{A}$ after admission clearly deserves more study.

In general, the present results indicate differing patterns of change associated with the three outcome groups. Group C, the high adjustment group, show a relatively low level of behavioural diability, appear to be unaffected by admission, and show little change over the first year of their stay. This raises the question whether they needed the degree of care provided by Part III accommodation. In contrast, Group B were somewhat more disabled, and showed a pattern of consistent cognitive and behavioural decline during the year. Their status one year later clearly indicates their need for the institutional care provided. Finally, Group A represents a poor outcome group, whose defining characteristic appears to be a significant increase in rated behavioural disability immediately after admission. In this study we were unable, however, to identify factors which might be responsible for this sudden drop.

It seems clear from these findings that most elderly people are not necessarily adversely affected by admission to Part III accommodation. The previously reported 'negative relocation effect' may be confined to a small group of elderly people, but for them the apparent decrease in behavioural competence after admission seems to have prognostic implications-that is, they show increased vulnerability to the risk of mortality and of permanent hospitalisation in the following year.

\section{Conclusions}

The main purpose of this study was to identify patterns of adjustment in residents newly admitted to Part III accommodation. The 'negative relocation effect' often remarked in the literature was observed to operate for one group of residents, who showed a particularly poor outcome in terms of death and/or hospitalisation, but it was not observed as a general phenomenon. Indeed, for most of the residents, two types of outcome could be observed. For half of them, their level of functional disability was initially higher, and, as a group, they showed a clearly identifiable pattern of decline during their stay. For the other half, their initial disability was low, and remained low throughout. Employing a pre-admission score of seven or under on the SSGRS, some $81 \%$ of the high adjustment/minimal deterioration could be so identified, with $71 \%$ of the remainder correctly identified as 'low' adjustment/increased deterioration. The possibility of employing the rating scale in such pre-admission screening, or as a 'vulnerability' index, deserves further investigation.

We thank the staff of the North Yorkshire Social Services Department and in particular the staff and residents of the Home for the Elderly in Tan Pit Lane, Easingwold.

Reprints from A. H. Pattie, Clifton Hospital, York.

\section{References}

Coleman, P. G. (1975). Social gerontology in England, Wales and Scotland: a review of recent and current research. The Gerontologist, 15, 219-229.

Department of Health and Social Security (1977). Residential Homes for the Elderly-Arrangements for Health Care. A Memorandum of Guidance. Welsh Office: Cardiff.

Gilleard, C. J., and Pattie, A. H. (1977). The Stockton Geriatric Rating Scale: A shortened version with British normative data. British Journal of Psychiatry, 131, 90-94.

Lawton, M. P., and Nahemow, L. (1973). Ecology and the ageing process. In The Psychologyof Adult Development and Ageing, pp. 619-674. Edited by C. Eisdorfer and M. P. Lawton. American Psychological Association: Washington DC.

Miller, D., and Lieberman, M. R. (1965). The relationships of affect state and adaptive capacity to reactions to stress. Journal of Gerontology, 20, 492-497.

Pattie, A. H., and Gilleard, C. J. (1975). 'A brief psychogeriatric assessment schedule: validation against psychiatric diagnosis and discharge from hospital.' British Journal of Psychiatry, 127, 489-493. 